\title{
Sensory denervation with capsaicin reduces ovarian follicular development and delays the onset of puberty in guinea pigs*
}

\author{
Victorino Alatriste ${ }^{1}$, Irma Herrera-Camacho ${ }^{2}$, María I. Martínez ${ }^{1}$, Ilhicamina D. Limón ${ }^{1}$, \\ Oscar González-Flores ${ }^{3}$, Félix Luna ${ }^{1 \#}$ \\ ${ }^{1}$ Departamento de Farmacia, FCQ-BUAP, Puebla, México; ${ }^{\#}$ Corresponding Author: felix.lunam@hotmail.com \\ ${ }^{2}$ Centro de Química, ICUAP, Puebla, México \\ ${ }^{3}$ Centro de Investigación en Reproducción Animal, UAT-CINVESTAV, Tlaxcala, México
}

Received 22 June 2013; revised 30 July 2013; accepted 15 August 2013

Copyright (C) 2013 Victorino Alatriste et al. This is an open access article distributed under the Creative Commons Attribution License, which permits unrestricted use, distribution, and reproduction in any medium, provided the original work is properly cited.

\begin{abstract}
Introduction: It has been documented that mammalian ovaries receive sympathetic, parasympathetic and sensory nerve fibers. The aim of this work was to investigate the effects of sensory denervation with capsaicin at the first vaginal opening (FVO) on follicular development and the expression of TRPV1 receptors in ovary cells as well as in the dorsal root ganglia (DRGs) and lumbar dorsal spinal cord neurons of guinea pigs. The DRGs and lumbar dorsal spinal cord neurons serve as a nerve connection from the ovaries to the CNS. Materials and Methods: Female guinea pigs received a subcutaneous injection of capsaicin $(30 \mathrm{mM})$ at 10 days of age (P10), while control animals were injected with vehicle. Using light microscopy, we counted healthy preantral follicles (HPF), healthy antral follicles (HAF), atretic preantral follicles (APF), and atretic antral follicles (AAF) in the ovaries at the FVO, and the numbers of TRPV1-positive cells were counted in the ovarian follicles, DRGs, and lumbar dorsal spinal cord (L2-L4) neurons by immunohistochemistry. Results: Guinea pigs treated with capsaicin showed a significant delay of FVO in comparison with the control animals (36 vs. 44 days). In the ovaries, the number of preantral and antral follicles decreased significantly. Additionally, the number of TRPV1-positive theca-interstitial cells of the antral follicles was reduced significantly,
\end{abstract}

\footnotetext{
*Competing interests: The authors declare that they have no competing interests.

Authors' contributions: All authors read and approved the final manuscript.
}

and the number of TRPV1-positive neurons in the DRGs and lumbar dorsal spinal cord (L2-L4) decreased. Thus, we showed that TRPV1 receptors throughout the sensory fibers modulate ovarian follicular development and the onset of puberty in guinea pigs. Conclusion: Sensory denervation decreases ovarian follicular development and delays the onset of puberty of guinea pigs. Our data support the idea that through TRPV1 receptors, ovarian afferent fibers sense local stimuli that are sent to the CNS.

Keywords: TRPV1 Receptors; Capsaicin; DRG; Spinal Cord; Ovary; Guinea Pigs

\section{INTRODUCTION}

An ovary receives its nerve supply from different sources of the autonomic or sensory branches of the peripheral nervous system [1-3]. Some of these sensory neurons are localized in DRGs, specifically from Th11-L5 [2,4,5], and display immunoreactivity for peptides such as calcitonin gene-related peptide (CGRP), substance P (SP), and neuropeptide Y (NPY) [6,7]. Several studies have shown that ovarian afferent nerves, in addition to their basic function in the transmission of sensory modalities from the ovary to the spinal cord, also play an important role in local mechanisms for steroidogenesis, ovulation and vascular tone regulation $[8,9]$.

Furthermore, it has been reported that TRPV1 and NGF receptors (TrkA and p75) are expressed in both sympathetic and sensory fibers that innervate reproductive organs $[6,10]$. In the ovarian follicles, NGF is synthesized and released from theca and granulosa cells [8] and stimulates follicular development and steroid production 
[11-13]. In particular, the administration of antibodies to nerve growth factor (NGF $\mathrm{Ab}$ ) in neonatal rats resulted in failure of the sympathetic nerves due to a reduction in the noradrenaline (NA) level and also produced a partial loss of sensory innervation measured by the CGRP level [8]. In addition, follicular growth was stunted, and the production of progesterone and estradiol was reduced [8]. In immature rats, the same treatment resulted in a delay of the first ovulation and an increase in the plasma LH level [14]. Administration of capsaicin in rats permanently destroyed the sensory fibers, and the proportion of dorsal horn neurons that exhibit slow excitatory transmission was markedly reduced [15], increasing follicular atresia [16] but decreasing estradiol and progesterone secretion from the ovaries [17].

To date, numerous studies on ovarian innervation have shown a close relationship between NA and sympathetic fibers, but a small number of studies have been performed on the sensory fibers and their transmitters in the ovarian system $[8,18]$. Additionally, these studies used tyrosine hydroxylase (TH), NGF and its receptor TrkA, and p75, and peptides, such as NPY, CGRP, and SP, among others, as markers $[13,19,20]$. In contrast, the TRPV1 receptors have not been studied in regards to ovarian nerve innervation even though they are essential for sensory nerve transmission. The TRPV1 receptors are localized in both pre- and paravertebral sympathetic neurons that project to the uterus and ovary [21-23], in the celiac ganglion [24] as well as in sympathetic chain ganglia [25] of neurons supplying the ovaries $[1,2,4]$. TRPV1 and NGF receptors are functionally interrelated in modulating peptide release and plasticity of peripheral nerve fibers [2628]. In uterine cells, the activation of TrkA receptors increases pain sensation mediated by TRPV1 receptors [29], whereas in the urinary bladder cells promote the overactivity response [10]. Additionally, presently there are no reports on the expression of TRPV1 receptors in ovary cells, but these receptors are very important for transmission and cell communication.

The purpose of our study was to investigate the role of ovarian sensory innervation on follicular development and the onset of puberty in the guinea pig. To achieve this goal, sensorial denervation with capsaicin (the specific ligand for TRPV1 receptors) was performed at P10. Here, we tested the hypothesis that ovarian follicular development and the onset of puberty are modulated by sensory fibers mediated by TRPV1 receptors. At first vaginal opening, we evaluated follicular development by light microscopy and TRPV1 receptors by immunocytochemistry in the ovaries, DRGs and dorsal lumbar spinal cord (L2-L4). DRGs and the dorsal lumbar spinal cord (L2-L4) are afferent cellular structures from the ovaries to the SNC $[2,4,5]$. Partial results were published at a neuroscience meeting in Washington DC, USA [30].

\section{MATERIALS AND METHODS}

\subsection{Animals and Treatment with Capsaicin}

All of the procedures described in this work were approved by the BUAP Animal Care Committee and adhered to governmental guidelines (Mexican Council for Animal Care, Norma Oficial Mexicana NOM-062-ZOO1999). The local guidelines were also in accordance with the National Institutes of Health Guide for the Care and Use of Laboratory Animals of the USA. All efforts were made to minimize animal suffering and to reduce the number of animals used. The Hartley guinea pigs (Cavia porcellus) were housed in groups (4 animals per cage) under a dark-light cycle of $12-12 \mathrm{~h}$ with a room temperature of $22 \pm 2$ degrees Celsius. The animals had free access to food and potable water, which was supplemented with vitamin $\mathrm{C}$.

We used twenty-four female guinea pigs randomly divided into four groups $(n=6)$. The animals of the first and second group were used for ovary collection, sampling of DRGs and lumbar dorsal spinal cord (L2-L4) for immunocytochemistry and evaluation of the expression of TRPV1 receptors with basal conditions at P10 or FVO. The animals of the third group were administered capsaicin $(30 \mathrm{mM})$ by subcutaneous injection in the upper part of the back at P10, and the animals of the fourth group were administered vehicle (1\% ethanol and $99 \%$ isotonic saline solution, $\mathrm{pH}$ 7.4), and samples were collected at FVO. FVO was defined as the complete loss of the vaginal membrane. In the guinea pig strain used under the described environmental conditions, FVO occurred at 36 days of age (P36) and marked the onset of puberty. At $\mathrm{P} 10$ or FVO, the experimental guinea pigs were sacrificed with $\mathrm{CO}_{2}$.

\subsection{Immunohistochemistry and Semiquantification of the TRPV1 Receptors in Ovaries, DRGs and Lumbar Dorsal Spinal Cord (L2-L4)}

The animals from each experimental group were sacrificed with $\mathrm{CO}_{2}$ and perfused with intracardiac saline solution $(\mathrm{NaCl}, 0.9 \%)$ followed by paraformaldehyde $(4 \%)$ in PBS, pH 7.4 (PF-PBS solution). The ovaries, DRGs (L2-L4) and lumbar spinal cord (L2-L4) were removed and post-fixed in PF-PBS solution, subsequently embedded in paraffin and then sectioned with a Leica SM2010R microtome $(5 \mu \mathrm{m})$ for immunohistochemistry. The sections were treated with xylene and ethanol and then washed with PBS solution. The sections were blocked with bovine albumin (IgG-free), treated with Triton X-100 and then washed with PBS at 24 degrees Celsius. The samples were incubated with the anti-capsaicin receptor (1:50, Millipore, USA) overnight at 4 degrees Celsius and then incubated with a secondary antibody (FITC) (IgG- 
free from goat; 1:250, Millipore, USA) for 2 hours at room temperature. To visualize the nucleus, the sections were incubated with propidium iodide (1:3000, Millipore, USA) for 2 minutes. The specificity of the TRPV1 antibody was confirmed in separate experiments with additional negative controls, including tissue sections incubated in the absence of primary antibody. All sections were mounted on microscope slides with mounting fluid (Millipore, USA) and then observed under a Leica fluorescence microscope.

We analyzed ovary, DRG or spinal cord tissue sections from five different animals with three repeat analyses for each structure. The images were captured with a Leica-DFC325 camera, and the data were stored on the PC hardware. For five different tissues, we counted the positive cells in five representative fields of each tissue section using the cell counter tool from NIH ImageJ software. From a qualitative point of view, the following three levels of fluorescence intensity were identified: light, medium and high. The cells were considered positive when they had a strong green signal, and negative cells were those that had a light or medium green signal. The final quality score was assessed using the software measure tool; the cells were positive when the measure was $\geq 50$ arbitrary units, and the cells were negative when the measure was $\leq 49$ arbitrary units.

\subsection{Morphological Analysis and Amount of Follicles in the Ovary}

The ovaries used for immunohistochemistry were also used for morphological examination and to count the follicles. The ovaries embedded in paraffin were serial sectioned with a microtome in $5 \mu \mathrm{m}$ histological slides; collecting three histological slices until complete ovary section. The histological sections were stained with hematoxylin-eosin and treated by common procedures. All sections were mounted on microscope slides with synthetic resin (Sigma, USA) and subsequently observed under a Zeiss light microscope. The images were captured with a Canon camera, and data were stored on the PC hardware. For morphological examination and ovarian follicle classification, we used previously published criteria [31,32] grouping the ovarian follicles into four categories; healthy preantral follicles (HPF), healthy antral follicles (HAF), atretic preantral follicles (APF) and atretic antral follicles (AAF).

\subsection{Statistical Analysis}

Data on the number of follicles, the number of TRPV1positive cells and the onset of puberty age were analyzed using ANOVA followed by the Mann-Whitney U-test. All data were expressed as the means \pm SEM, and when the probability was less than $5 \%$, it was considered sig- nificant.

\section{RESULTS}

\subsection{Differential Expression of TRPV1 Receptors in the Ovary, DRGs and Lumbar Spinal Cord (L2-L4) of Untouched Guinea Pig at P10 vs. FVO}

TRPV1 receptors were localized in the theca-interstitial cells of the ovary follicles, predominantly in healthy antral follicles (Figure 1(a)). TRPV1-positive theca-in terstitial cells in healthy preantral and atretic follicles (preantral and antral) were also detected; however, the immunofluorescent signals were very low. We also found blood vessel positive cells (data not showed). At P10, in healthy antral follicles, the immunofluorescent signal for TRPV1 receptors was low, but was increased $188 \%$ above control at FVO (Figure 1(b)) $\left(^{*} \mathrm{p}<0.05\right.$, ANOVA followed by a Mann-Whitney U-test). In DRGs, we detected TRPV1-positive small, medium and big neurons (Figure $1(\mathbf{a})$ ) in a proportion of 4:2.1. At P10, the number of TRPV1-positive small, medium and big neurons was low and increased $121 \%, 100 \%$ and $91 \%$ at $\mathrm{FVO}$, respectively (Figure 1(c)) ( ${ }^{*} \mathrm{p}<0.05$, ANOVA followed by a MannWhitney U-test). In lumbar spinal cords (L2-L4), the TRPV1 immunofluorescent signal was abundant in dorsal horn region neurons, but was not limited to this area as immunofluorescent cells were detected in the peripheral white matter of the spinal cord where there are more unmyelinated than myelinated axons (Figure 1(a)). As before, the expression of TRPV1 receptors in ovary and DRG cells in the spinal cord of guinea pigs was lower (less positive neurons) at $\mathrm{P} 10$ than at $\mathrm{FVO}$ (increasing 103\%) (Figure 1(d)) $\left({ }^{*} \mathrm{p}<0.05\right.$, ANOVA followed by a Mann-Whitney U-test).

\subsection{Capsaicin Delayed the Onset of Puberty}

In the guinea pigs injected with capsaicin, the FVO was delayed and occurred at $44 \pm 1.8$ days of age versus $36 \pm 3$ days of age in the animals injected with vehicle (Figure 2) $\left({ }^{*} \mathrm{p}<0.05\right.$, ANOVA followed by a MannWhitney U-test).

\subsection{Capsaicin Decreased the Ovarian Follicular Development}

In comparison to the animals injected with the vehicle, the numbers of HPFs, APFs, HAFs, and AAFs in the ovaries of guinea pigs injected with capsaicin decreased $50 \%, 66 \%, 27 \%$ and $52 \%$, respectively (Figure $3(\mathrm{a}))\left(^{*} \mathrm{p}\right.$ $<0.05$, ANOVA followed by a Mann-Whitney U-test). A similar result was obtained when the ovarian follicles were grouped only as healthy or atretic follicles. In this case, the number of healthy follicles and atretic follicles 

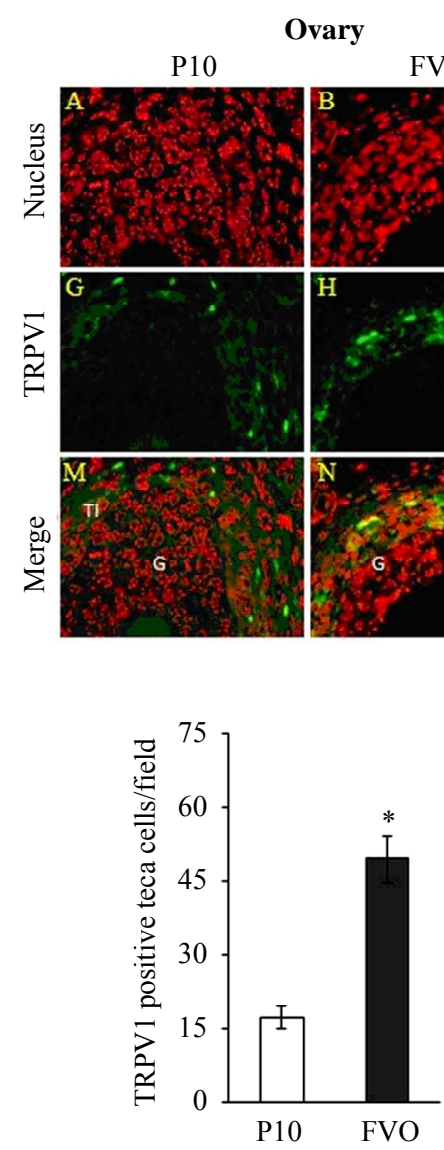

(b)


(a)

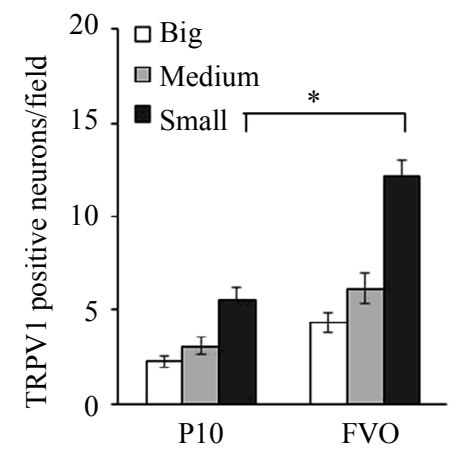

(c)
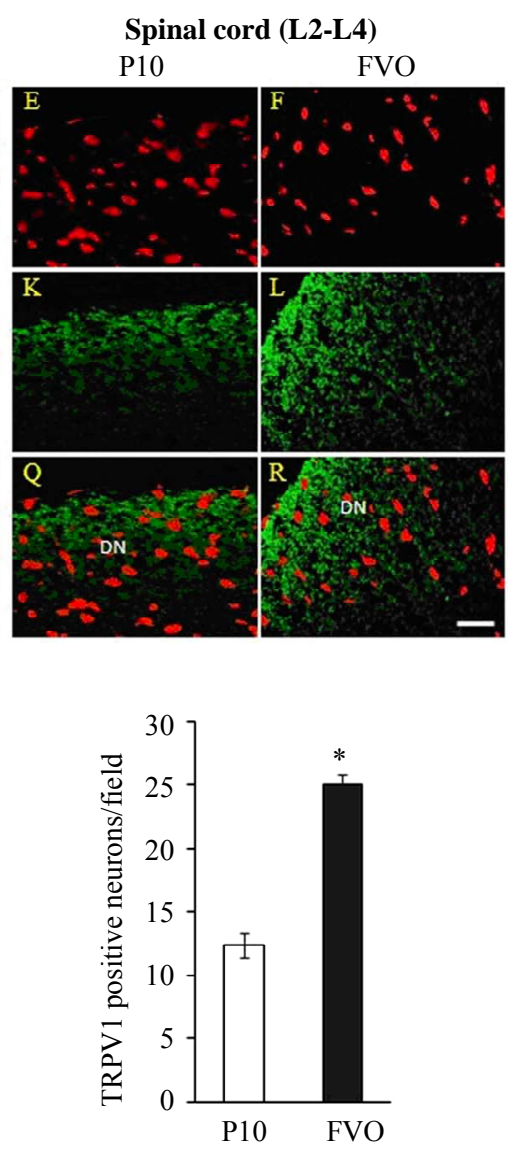

(d)

Figure 1. Immunohistochemistry for the TRPV1 receptors in ovaries, DRG (L2-L4) and lumbar dorsal spinal cord (L2-L4) at P10 and FV0 of untouched guinea pigs (a), Immunohistochemistry for the TRPV1 receptors in tissues of the guinea pig (at P10 and FVO). We show the cell nucleus in red, stained with propidium iodide (AA, AB, AC, AD, AE and AF), TRPV1 receptors in green, marked with FITC ( $\mathrm{AG}, \mathrm{AH}, \mathrm{AI}, \mathrm{AJ}, \mathrm{AK}$ and $\mathrm{AL})$, and the merged images (AM, AN, $\mathrm{AO}, \mathrm{AP}, \mathrm{AQ}$, and AR). In ovary, theca-interstitial cells (TI) of the healthy antral follicles and granulosa cells (G). DRG (L2-L4): big (white arrow), medium (open arrow) and small neurons (arrowhead). Lumbar dorsal spinal cord neurons (DN). Graphic illustration of the number of TRPV1-positive cells in the ovaries (b), DRG (c) and lumbar dorsal spinal cord (d). The data are presented as the means and SEM $(n=5)$. Scale bar is equivalent to $10 \mu \mathrm{m}, \mathrm{p}<0.05$, ANOVA followed by Mann-Whitney U-test.

decreased $37 \%$ and $57 \%$, respectively (Figure 3(b)) $\left({ }^{*} \mathrm{p}\right.$ $<0.05$, ANOVA followed by a Mann-Whitney U-test).

\subsection{Capsaicin Decreased the Expression of TRPV1 Receptors in Ovarian Follicle Cells, DRGs and Lumbar Spinal Cord (L2-L4) Neurons}

To determine any changes in expression of the TRPV1 receptor after capsaicin administration, we localized TRPV1 receptors in the ovary cells, DRGs and lumbar dorsal spinal cord neurons of guinea pigs injected with capsaicin or vehicle by immunocytochemistry (Figure 4(a)). In comparison to animals injected with vehicle, the number of TRPV1-positive theca-interstitial cells in the healthy antral follicles decreased $58 \%$ in the ovary of guinea pigs injected with capsaicin (Figure 4(b)) $\left(^{*} \mathrm{p}<0.05\right.$, ANOVA followed by a Mann-Whitney U-test). A similar result was obtained in small, medium and big DRG neurons where the number of TRPV1-positive neurons was reduced 47\%, 17\% and 34\%, respectively (Figure 4(c)) $\left({ }^{*} \mathrm{p}\right.$ $<0.05$, ANOVA followed by a Mann-Whitney U-test). In the lumbar spinal cord (L2-L4) of the animals injected with capsaicin, the number of TRPV1-positive neurons decreased 44\% (Figures 4(a) and (d)) $\left(^{*} \mathrm{p}<0.05\right.$, ANOVA followed by a Mann-Whitney U-test).

\section{DISCUSSION}

In this report, we showed the effects of sensory denervation by capsaicin on ovarian follicular development and the onset of puberty of guinea pigs. Furthermore, we evaluated the expression of TRPV1 receptors in the ovary cells, DRGs and lumbar dorsal spinal cord (L2-L4) neurons by immunocytochemistry in basal conditions (untouched animals) and after capsaicin injection or ve- 


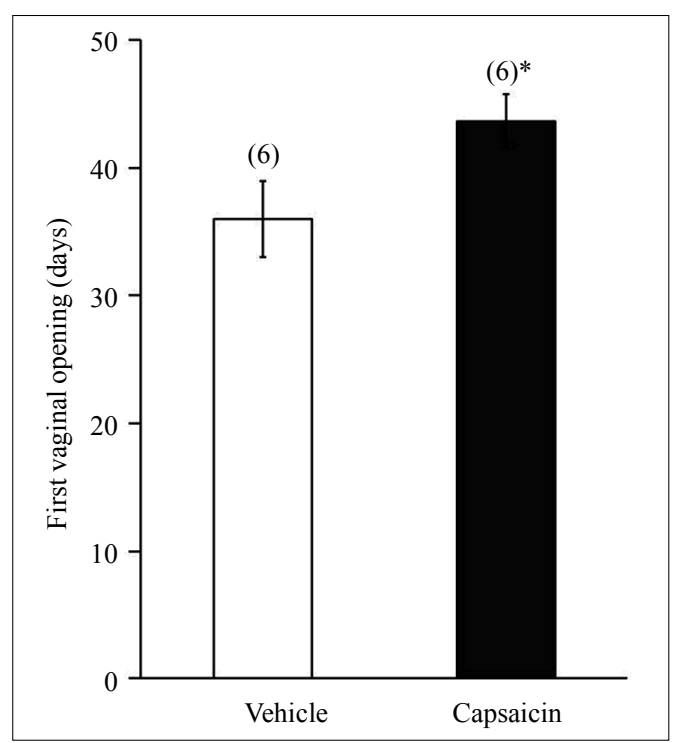

Figure 2. The FVO of the guinea pigs treated with capsaicin. FVO in animals administered vehicle or capsaicin $(30 \mathrm{mM})$ by subcutaneous injection with at P10, ${ }^{*} \mathrm{p}<0.05$, ANOVA followed by Mann-Whitney U-test.

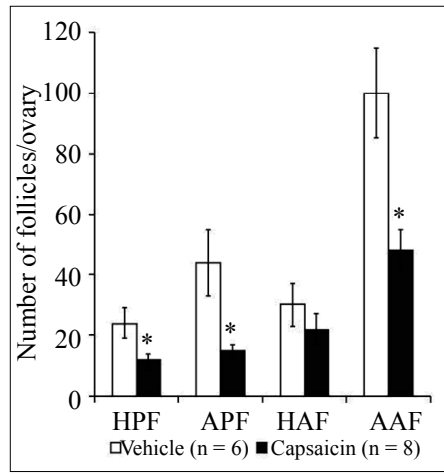

(a)

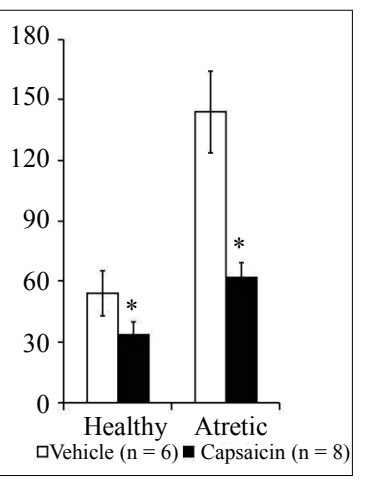

(b)
Figure 3. Number of the follicles in ovary of the guinea pigs treated with capsaicin. Ovarian follicles in animals administered vehicle or capsaicin $(30 \mathrm{mM})$ by subcutaneous injection at P10 and autopsied at FVO. (a) Healthy preantral follicles (HPF), atretic preantral follicles (APF), healthy antral follicles (HAF) and atretic antral follicles (AAF). (b) Healthy and atretic follicles of the ovaries, ${ }^{*} \mathrm{p}<0.05$, ANOVA followed by MannWhitney U-test.

hicle. These data are the first evidence of the presence of TRPV1 receptors in ovary cells and their participation in follicular development and the onset of puberty.

The fact that the FVO was delayed in the guinea pigs treated with capsaicin suggests that sensory fibers have a role in the hypothalamus-pituitary-ovary axis, which contributes to the onset of puberty in these animals. Previously, it was reported that capsaicin treatment in neonatal rats did not altered the onset of puberty, which was measured by the onset of first estrous; however, the number of ovarian follicles (preantral and antral) and estradiol in the serum of the neonatal rats decreased after neurotoxin administration [16]. The disagreement of our results with this report in rats could be due to the different animal models used because guinea pigs and rats exhibit fundamental differences in peripheral innervation. Guinea pigs have abundant peripheral innervation in visceral organs in contrast to rats, which have scarce peripheral innervation $[33,34]$. Additionally, guinea pigs have shown high responses to the induction of chemical denervation [35]. In our study, the FVO delay was in concordance with a reduced number of preantral and antral follicles obtained in the guinea pig ovaries treated with capsaicin. Although, estradiol was not measured, we can infer a diminution in its concentration because the antral follicles were reduced, which are the principal source of this steroid hormone [11-13]. This interpretation is in agreement with data obtained in the rat by other authors; denervation induced with capsaicin was found to reduce estradiol in the serum [16]. Additionally, it has been reported that follicular development and ovarian steroidogenesis are regulated by growth factors, such as NGF. This was indicated by a reduction in the transition of preantral to antral follicles in response to NGF Ab treatment [8], a response that was mediated by low affinity receptors (p75NGFR) localized in the theca cells of the follicles $[18,36]$, where NGF also increased FSHRs to stimulate follicular development $[12,37]$. The reduced number of follicles obtained in the guinea pigs after capsaicin administration, was linked with a reduced number of TRPV1-positive theca-interstitial cells in the healthy antral follicles.

These data support the hypothesis that capsaicin causes a primary failure in follicular development and a subsequent reduction in steroidogenesis. Ovarian thecainterstitial cells are essential to steroidogenesis because theca cells provide androgen substrates for aromatization and estradiol production by granulosa cells. Theca cells express intense staining for 3 beta-hydroxysteroid dehydrogenase ( 3 beta-HSD), an enzyme required for the biosynthesis of steroid hormones in immature and adult rats during follicular development [38]. Likewise, in thecainterstitial cells, growth factors such as NGF, activate androgen production and stimulate follicular development $[11,12]$. Also, NFG has been suggested as an activator of androgen production in induced polycystic ovaries in rats [13]. The reduced follicular development and the delayed onset of puberty obtained in the guinea pigs treated with capsaicin could also be the result of a decreased number of TRPV1-positive neurons in the DRGs and in the lumbar dorsal spinal cord, which was indicated by a reduction in the DRG small neurons and the neurons of the substantia gelatinosa (SG; lamina II) of the spinal cord. The DRG small neurons are $\mathrm{C}$ primary fibers, the principal group of sensory neurons $[39,40]$. These results suggest 

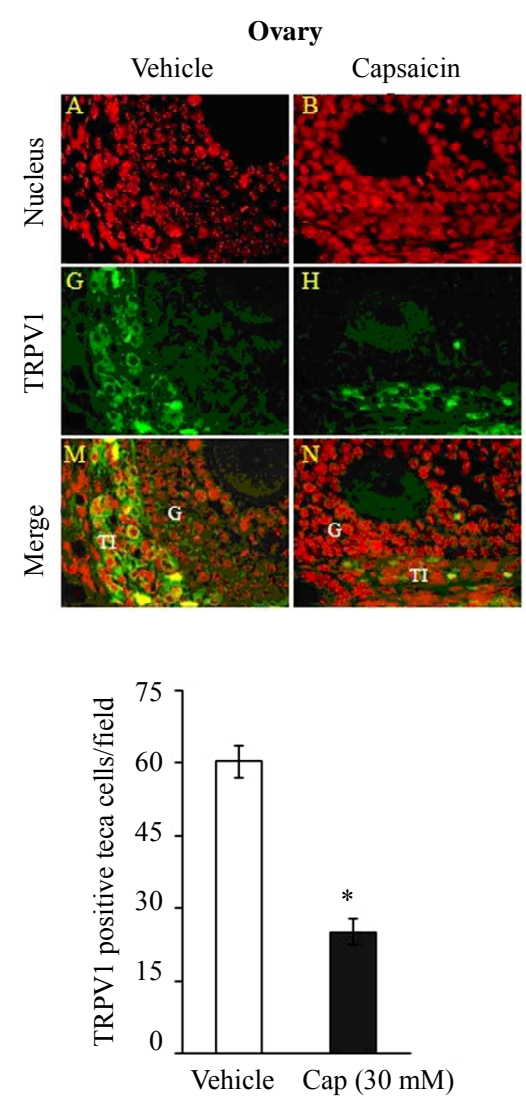

(b)

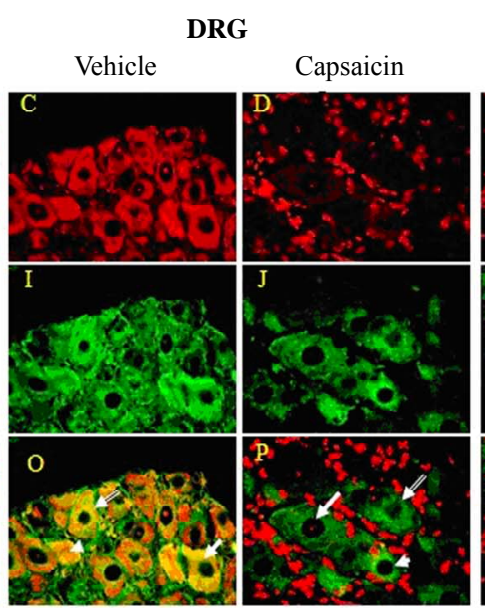

(a)

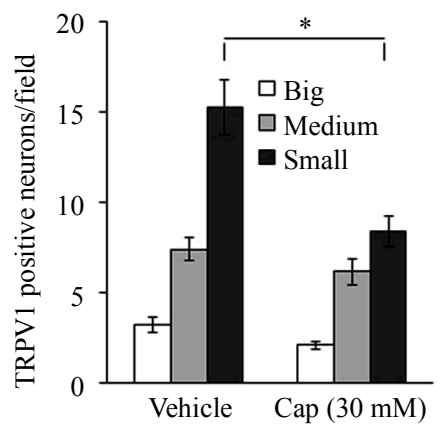

(c)
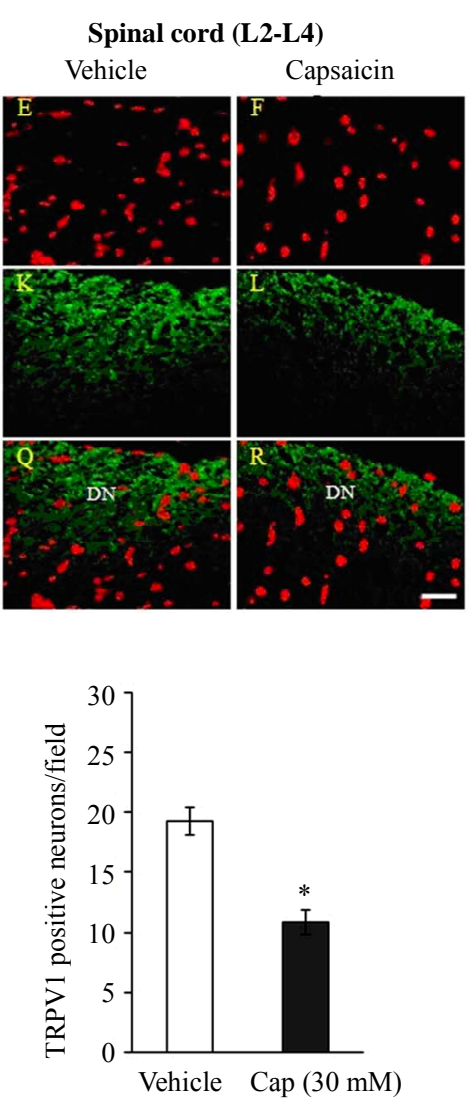

(d)

Figure 4. Immunohistochemistry for the TRPV1 receptors in ovaries, DRG and lumbar dorsal spinal cord (L2-L4) of guinea pigs treated with capsaicin Immunohistochemistry for the TRPV1 receptors in tissues of the animals administered vehicle or capsaicin $(30 \mathrm{mM})$ by subcutaneous injection at P10 and autopsied at first vaginal opening (FVO). (a) We show the cell nucleus in red, stained with propidium iodide (AA, AB, AC, AD, AE and AF), TRPV1 receptors in green, marked with FITC (AG, $\mathrm{AH}, \mathrm{AI}, \mathrm{AJ}, \mathrm{AK}$ and $\mathrm{AL})$, and the merged images (AM, AN, AO, AP, AQ and AR). Ovary theca-interstitial cells (TI) of healthy antral follicles and granulosa cells (G). DRG (L2-L4): big neuron (white arrow), medium (open arrow) and small neurons (arrowhead). Lumbar dorsal spinal cord neurons (DN). Graphic illustration of the number of TRPV1-positive cells in the ovaries (b), DRGs (c) and lumbar spinal cord (d). The data are presented as the means and SEM $(n=5)$. Scale bar is equivalent to $10 \mu \mathrm{m},{ }^{*} \mathrm{p}<0.05$, ANOVA followed by Mann-Whitney U-test.

that, in guinea pigs, the denervation induced by capsaicin blocks the afferent transmission to supra-spinal structures of the CNS. This interpretation was reinforced by the fact that FVO occurred later when the animals were treated with capsaicin. Furthermore, in the ovaries of the untouched guinea pigs, the number of TRPV1-positive cells was significantly elevated at FVO, suggesting that the ovarian sensory fibers are highly developed at the onset of puberty.

Because the expression of TRPV1 receptors was unknown in the ovary, another focus of our study was to evaluate the expression of TRPV1 receptors in basal conditions by immunocytochemistry. We also evaluated the level of TRPV1 transcripts by RT-PCR amplification (data not yet published). The TRPV1 receptors were found in the theca-interstitial cells of the follicles, with low expression at P10 that increased at the onset of pu- berty (FVO). These results are consistent with the expression of TRPV1 receptors in many tissues depending on cell type and activity $[41,42]$. In retina cells and pulmonary arterial smooth muscle cells, TRPV1 receptors promote cell proliferation and migration by MAPK intracellular signal activation $[43,44]$. In the ovary, this mechanism may be possible, but it has not yet been tested. In DRGs, we also found a high number of TRP-V1-positive small neurons in contrast to medium or big positive neurons, and the TRPV1 expression also increased at FVO. These data are in agreement with previous studies, most likely because small neurons are C-fibers, the major population of sensory nerves [45]. Similarly, the high number of TRPV1-positive neurons that we observed in the dorsal horn of the spinal cord has been previously obtained because the dorsal horn is the anatomical structure where afferent terminals converge on the way to the spi- 
nal cord [46]. The expression of TRPV1 receptors was high in DRG small neurons in rats [47] and decreased with capsaicin, specifically in small $\mathrm{C}$ and A-delta fibers; that expression that has been restored with growth factors, such as NGF, in previous studies [26]. Previously, it has been suggested that DRG and dorsal spinal cord (T12-L5) neurons are important for the connection between the ovary and the supra-spinal structures of the CNS [3,5].

Additionally, it has been demonstrated that TRPV1 and NGF receptors are co-expressed in sensory fibers and are functionally interrelated through the modulation of the development of neurons, peptide release (CGRP, SP) and sensation of the different qualities that activate primary afferent fibers $[28,48]$. Although, the effects of denervation on follicular development were evaluated, we can also infer changes in the neurochemical organization pattern of the ovarian sensory fibers due to the lower number of TRPV1-positive neurons in DRG and spinal cord after capsaicin administration. It is recognized that, in sensory fibers, the activity of TRPV1 receptors is augmented by NGF, increasing their plasticity and spontaneous activity [48-50]. Sensory fiber responses decreased with capsaicin and were restored with NGF [42]. In this manner, cell proliferation is decreased in carcinoma tumors when NGF is blocked, a response that is mediated by TRPV1 receptors [50].

Our data suggest that the sensory fibers modulate follicular development and the onset of puberty through TRPV1 receptors, and these receptors can be integrative sensors in the transmission of sensory modalities from the ovary to the CNS.

\section{CONCLUSION}

For the first time, we showed that, through TRPV1 receptors, sensory fibers modulate ovarian follicular development and the onset of puberty of the guinea pig.

\section{ACKNOWLEDGEMENTS}

This work was supported by VIEP-BUAP grants 2011-12, and Victorino Alatriste was supported by Consejo Nacional de Ciencia y Tecnología through the doctoral program, CONACYT/45680. We are grateful to Diego Luna for his English language editing.

\section{REFERENCES}

[1] Burden, H.W., Leonard, M., Smith, C.O. and Lawrence Jr. I.E. (1983) The sensory innervation of the ovary: A horseradish peroxidase study in the rat. Anatomical Record, 207, 623-627. http://dx.doi.org/10.1002/ar.1092070410

[2] Klein, C.M. and Burden, H.W. (1988) Anatomical localization of afferent and postganglionic sympathetic neurons innervating the ovary. Neuroscience Letters, 85, 217 222. http://dx.doi.org/10.1016/0304-3940(88)90354-0
[3] Gerendai, I., Tóth, I.E., Boldogköi, Z., Medveczky, I. and Halász, B. (2000) CNS structures presumably involved in vagal control of ovarian function. Journal of the Autonomic Nervous System, 80, 40-45.

http://dx.doi.org/10.1016/S0165-1838(00)00071-0

[4] Burden, H.W. and Zary, J.T. (2002) Localization of calretinin in the rat ovary and in relation to nerve cell bodies in dorsal root and paravertebral ganglia projecting to the ovary. Microscopy Research and Technique, 59, 490-494. http://dx.doi.org/10.1002/jemt.10226

[5] Jana, B., Lata, M., Bulc, M. and Całka, J. (2012) Long term estradiol-17 $\beta$ administration changes population of the dorsal root ganglia neurons innervating the ovary in the sexually mature gilts. Neuropeptides, 46, 157-165. http://dx.doi.org/10.1016/j.npep.2012.05.001

[6] Majewski, M., Sienkiewicz, W., Kaleczyc, J., Mayer, B., Czaja, K. and Łakomy, M. (1995) The distribution and colocalization of imunoreactivity to nitric oxide synthase, vasoactive intestinal polypeptide and substance $\mathrm{P}$ within nerve fibres supplying bovine and porcine genital organs. Cell and Tissue Research, 281, 445-464.

http://dx.doi.org/10.1007/BF00417862

[7] Shadiack, A.M., Sun, Y. and Zigmond, R.E. (2001) Nerve growth factor antiserum induces axotomy-like changes in neuropeptide expression in intact sympathetic and sensory neurons. The Journal of Neuroscience, 21, 363-371.

[8] Lara, H.E., Hill, D.F., Katz, K.H. and Ojeda, S.R. (1990) The gene encoding nerve growth factor is expressed in the immature rat ovary: Effect of denervation and hormonal treatment. Endocrinology, 126, 357-363.

http://dx.doi.org/10.1210/endo-126-1-357

[9] Gerendai, I. and Halász, B. (1997) Neuroendocrine asymmetry. Frontiers in Neuroendocrinology, 18, 354-381. http://dx.doi.org/10.1006/frne.1997.0154

[10] Kim, J.C., Kim, D.B., Seo, S.I., Park, Y.H. and Hwang, T.K. (2004) Nerve growth factor and vanilloid receptor expression, and detrusor instability, after relieving bladder outlet obstruction in rats. BJU International, 94, 915918. http://dx.doi.org/10.1111/j.1464-4096.2003.05059.x

[11] Dissen, G.A., Hill, D.F., Costa, M.E., Dees, W.L., Lara, H.E. and Ojeda, S.R. (1996) A role for trkA nerve growth factor receptors in mammalian ovulation. Endocrinology, 137, 198-209. http://dx.doi.org/10.1210/en.137.1.198

[12] Dissen, G.A., Lara, H.E., Leyton, V., Paredes, A., Hill, D.F., Costa, M.E., et al. (2000) Intraovarian excess of nerve growth factor increases androgen secretion and disrupts estrous cyclicity in the rat. Endocrinology, 141, 10731082. http://dx.doi.org/10.1210/en.141.3.1073

[13] Lara, H.E., Dissen, G.A., Leyton, V., Paredes, A., Fuenzalida, H., Fiedler, J.L., et al. (2000) An increased intraovarian synthesis of nerve growth factor and its low affinity receptor is a principal component of steroid-induced polycystic ovary in the rat. Endocrinology, 141, 1059-1072. http://dx.doi.org/10.1210/en.141.3.1059

[14] Lara, H.E., McDonald, J.K. and Ojeda, S.R. (1990) Involvement of nerve growth factor in female sexual development. Endocrinology, 126, 364-375. http://dx.doi.org/10.1210/endo-126-1-364

[15] Urbán, L., Willetts, J., Randić, M. and Papka, R.E. (1985) The acute and chronic effects of capsaicin on slow excitatory transmission in rat dorsal horn. Brain Research, 330, 390-396. http://dx.doi.org/10.1016/0006-8993(85)90705-X 
[16] Morán, C., Morales, L., Razo, R.S., Apolonio, J., Quiróz, U., Chavira R, et al. (2003) Effects of sensorial denervation induced by capsaicin injection at birth or on day three of life, on puberty, induced ovulation and pregnancy. Life Science, 73, 2113-2125.

http://dx.doi.org/10.1016/S0024-3205(03)00598-8

[17] Trujillo, A., Morales, L., Vargas, X., Alba, L. and Domínguez, R. (2004) Effects of capsaicin treatment on the regulation of ovarian compensatory hypertrophy and compensatory ovulation. Endocrine, 25, 155-162. http://dx.doi.org/10.1385/ENDO:25:2:155

[18] Dissen, G.A., Hill, D.F., Costa, M.E., Ma, Y.J. and Ojeda, S.R. (1991) Nerve growth factor receptors in the peripubertal rat ovary. Molecular Endocrinology, 5, 1642-1650. http://dx.doi.org/10.1210/mend-5-11-1642

[19] Calka, J., McDonald, J. K. and Ojeda, S.R. (1988) The innervation of the immature rat ovary by calcitonin generelated peptide. Biology of Reproduction, 39, 1215-1223. http://dx.doi.org/10.1095/biolreprod39.5.1215

[20] Kozłowska, A., Wojtkiewicz, J., Majewski, M. and Jana, B. (2011) Localization of substance P, calcitonin gene related peptide and galanin in the nerve fibers of porcine cystic ovaries. Folia Histochemica et Cytobiologica, 49, 622-630.

[21] Tokushige, N., Russell, P. and Black, K. (2010) Nerve fibers in ovarian endometriomas. Fertility Sterility, 94, 19441947. http://dx.doi.org/10.1016/j.fertnstert.2009.12.074

[22] Yu, S.Q. and Wang, D.H. (2011) Intrathecal injection of TRPV1 shRNA leads to increases in blood pressure in rats. Acta Physiologica (Oxford England), 203, 139-147. http://dx.doi.org/10.1111/j.1748-1716.2011.02285.x

[23] Liu, J., Liu, X., Duan, K., Zhang, Y. and Guo, S.W. (2012) The expression and functionality of transient receptor potential vanilloid 1 in ovarian endometriomas. Reproductive Sciences, 19, 1110-1124.

http://dx.doi.org/10.1177/1933719112443876

[24] Dawson, L.F., Phillips, J.K., Finch, P.M., Inglis, J.J. and Drummond, P.D. (2011) Expression of $\alpha 1$-adrenoceptors on peripheral nociceptive neurons. Neuroscience, 175, 300314. http://dx.doi.org/10.1016/j.neuroscience.2010.11.064

[25] Christianson, J.A., Traub, R.J. and Davis, B.M. (2006) Differences in spinal distribution and neurochemical phenotype of colonic afferents in mouse and rat. The Journal of Comparative Neurology, 494, 246-259. http://dx.doi.org/10.1002/cne.20816

[26] Ji, R.R., Samad, T.A., Jin, S.X., Schmoll, R. and Woolf, C.J. (2002) p38 MAPK activation by NGF in primary sensory neurons after inflammation increases TRPV1 levels and maintains heat hyperalgesia. Neuron, 36, 57-68. http://dx.doi.org/10.1016/S0896-6273(02)00908-X

[27] Bonnington, J.K. and McNaughton, P.A. (2003) Signalling pathways involved in the sensitisation of mouse nociceptive neurones by nerve growth factor. The Journal of Physiology, 551, 433-446.

http://dx.doi.org/10.1113/jphysiol.2003.039990

[28] Gopinath, P., Wan, E., Holdcroft, A., Facer, P., Davis, J.B., Smith, G.D., et al. (2005) Increased capsaicin receptor TRPV1 in skin nerve fibres and related vanilloid recaptors TRPV3 and TRPV4 in keratinocytes in human breast pain. BMC Womens Health, 5, 2.

http://dx.doi.org/10.1186/1472-6874-5-2

[29] Tingaker, B.K., Ekman-Ordeberg, G., Facer, P., Irestedt, L. and Anand, P. (2008) Influence of pregnancy and labor on the occurrence of nerve fibers expressing the capsaicin receptor TRPV1 in human corpus and cervix uteri. Reproductive Biology and Endocrinology: $R B \& E, \mathbf{6}, 8$. http://dx.doi.org/10.1186/1477-7827-6-8

[30] Alatriste, V., Herrera-Camacho, I., Torres-Soto, M., Gomez-Camarillo, M.A., Gonzalez-Flores, O., Limon, I.D., et al. (2011) Differential development of TRPV1-expressing reproductive gland and sensory nerves; ovary, dorsal root ganglion, and lumbar spinal cord of the guinea pig. Neuroscience Meeting, Washington DC.

[31] Kroemer, G., El-Deiry, W.S., Golstein, P., Peter, M.E., Vaux, D., Vandenabeele, P., et al. (2005) Classification of cell death: Recommendations of the Nomenclature Committee on Cell Death. Cell Death and Differentiation, 12, 1463-1467. http://dx.doi.org/10.1038/sj.cdd.4401724

[32] Wang, W., Liu, H.L., Tian, W., Zhang, F.F., Gong, Y., Chen, J.W., et al. (2010) Morphologic observation and classification criteria of atretic follicles in guinea pigs. Journal of Zhejiang University, Science B, 11, 307-314. http://dx.doi.org/10.1631/jzus.B0900391

[33] Metz, W. and Forssmann, W.G. (1980) Innervation of the liver in guinea pig and rat. Anatomy and Embryology, 160, 239-252. http://dx.doi.org/10.1007/BF00305105

[34] Nikkinen, A., Uusitalo, H., Lehtosalo, J.I. and Palkama, A. (1985) Distribution of adrenergic nerves in the lacrimal glands of guinea-pig and rat. Experimental Eye Research, 40, 751-756.

http://dx.doi.org/10.1016/0014-4835(85)90144-7

[35] Birmingham, A.T. (1970) Sympathetic denervation of the smooth muscle of the vas deferens. The Journal of Physiology, 206, 645-661.

[36] Dissen, G.A., Hirshfield, A.N., Malamed, S. and Ojeda, S.R. (1995) Expression of neurotrophins and their recaptors in the mammalian ovary is developmentally regulated: Changes at the time of folliculogenesis. Endocrinology, 136, 4681-4692. http://dx.doi.org/10.1210/en.136.10.4681

[37] Romero, C., Paredes, A., Dissen, G.A. and Ojeda S.R. (2002) Nerve growth factor induces the expression of functional FSH receptors in newly formed follicles of the rat ovary. Endocrinology, 143, 1485-1494. http://dx.doi.org/10.1210/en.143.4.1485

[38] Teerds, K.J. and Dorrington, J.H. (1993) Immunohistochemical localization of 3 beta-hydroxysteroid dehydrogenase in the rat ovary during follicular development and atresia. Biology of Reproduction, 49, 989-996.

http://dx.doi.org/10.1095/biolreprod49.5.989

[39] Kumazawa, T. and Perl, E.R. (1978) Excitation of marginal and substantia gelatinosa neurons in the primate spinal cord: Indications of their place in dorsal horn functional organization. The Journal of Comparative Neuro$\log y, \mathbf{1 7 7}, 417-434$.

http://dx.doi.org/10.1002/cne.901770305

[40] Yoshimura, M. and Jessell, T.M. (1989) Primary afferentevoked synaptic responses and slow potential generation in rat substantia gelatinosa neurons in vitro. Journal of Neurophysiology, 62, 96-108.

[41] Fonseca, B.M., Correia-da-Silva, G., Taylor, A.H., Konje, J.C., Bell, S.C. and Teixeira, N.A. (2009) Spatio-temporal expression patterns of anandamide-binding receptors in rat implantation sites: evidence for a role of the endocannabinoid system during the period of placental development. Reproductive Biology and Endocrinology, 7, 121. 
http://dx.doi.org/10.1186/1477-7827-7-121

[42] Giannantoni, A., Conte, A., Farfariello, V., Proietti, S., Vianello, A., Nardicchi, V., et al. (2013) Onabotulinumtoxin-A intradetrusorial injections modulate bladder expression of NGF, TrkA, p75 and TRPV1 in patients with detrusor overactivity. Pharmacological Research, 68, 118-124. http://dx.doi.org/10.1016/j.phrs.2012.11.009

[43] Leonelli, M., Martins, D.O. and Britto, L.R. (2011) TRPV1 receptors modulate retinal development. International Journal of Developmental Neuroscience, 29, 405413. http://dx.doi.org/10.1016/j.ijdevneu.2011.03.002

[44] Martin, E., Dahan, D., Cardouat, G., Gillibert-Duplantier, J., Marthan, R., Savineau, J.P., et al. (2012) Involvement of TRPV1 and TRPV4 channels in migration of rat pulmonary arterial smooth muscle cells. Pflügers Archiv, 464, 261-272. http://dx.doi.org/10.1007/s00424-012-1136-5

[45] Kobayashi, K., Fukuoka, T., Obata, K., Yamanaka, H., Dai, Y., Tokunaga, A., et al. (2005) Distinct expression of TRPM8, TRPA1, and TRPV1 mRNAs in rat primary afferent neurons with adelta/c-fibers and colocalization with trk receptors. The journal of comparative neurology, 493, 596-606. http://dx.doi.org/10.1002/cne.20794

[46] Jankowski, M.P. and Koerber, H.R. (2010) Neurotrophic factors and nociceptor sensitization. In: Kruger, L. and Light, A.R., Eds., Translational Pain Research: From
Mouse to Man, CRC Press, Boca Raton. http://www.ncbi.nlm.nih.gov/books/NBK57265/

[47] Donnerer, J., Liebmann, I. and Schicho, R. (2005) Differential regulation of 3-beta-hydroxysteroid dehydrogenase and vanilloid receptor TRPV1 mRNA in sensory neurons by capsaicin and NGF. Pharmacology, 73, 97101. http://dx.doi.org/10.1159/000081625

[48] Obreja, O., Ringkamp, M., Turnquist, B., Hirth, M., Forsch, E., Rukwied, R., et al. (2011) Nerve growth factor selectively decreases activity-dependent conduc- tion slowing in mechano-insensitive C-nociceptors. Pain, 152, 2138-2146. http://dx.doi.org/10.1016/j.pain.2011.05.021

[49] Li, D., Ren, Y., Xu, X., Zou, X., Fang, L. and Lin, Q. (2008) Sensitization of primary afferent nociceptors induced by intradermal capsaicin involves the peripheral release of calcitonin gene-related Peptide driven by dorsal root reflexes. Journal of Pain, 9, 1155-1168. http://dx.doi.org/10.1016/i.jpain.2008.06.011

[50] Ye, Y., Dang, D., Zhang, J., Viet, C.T., Lam, D.K., Dolan, J.C., et al. (2011) Nerve growth factor links oral cancer progression, pain, and cachexia. Molecular Cancer Therapeutics, 10, 1667-1676. http://dx.doi.org/10.1158/1535-7163.MCT-11-0123

\section{LIST OF ABBREVIATIONS}

CGRP: Calcitonin gene related peptide

DRGs: Dorsal root ganglion

FVO: First vaginal opening

NGF: Nerve growth factor

NPY: Neuropeptide Y

SP: Substance P

TRPV1: Transient receptor potential vanilloid type 1

trkA: Tyrosine kinase A receptors 